\title{
EL ESTUDIO DE LAS ESTRUCTURAS DE PODER LOCAI. EN EL SIGLO XIX: ASPECTOS METODOLÓGICOS
}

\author{
por \\ ELISEU TOSCAS \\ Profesor de Enseñanza Secundaria en Cataluña
}

RESUMEN: El autor babla, en primer lugar, de las razones que contribuyen a explicar el renovado interés bistoriográfico por el análisis de las estructuras de poder local, $y$, en segundo lugar, y sobre todo, de algunos aspectos metodológicos a tener en cuenta en todo estudio de dichas estructuras en el siglo XIX.

P'ALABRAS CLAVE: Poder local. Metodología. Historiografia. Siglo XIX.

ABSTRACT: The autbor speaks, firstly, about the reasons a bich belp to explain the renewed bistoriographic interest in the analysis of the local power structures and, scondly and most importantly, about some methodological aspects to be taken into account in every study made on these above mentioned structures in the nineteenth century.

KEY WORDS: Municipal governments. Methodology. Historiography. XIXth century.

Ante todo, quiero dar las gracias al profesor Pedro Carasa por su amable invitación a dar esta charla. Hablaré, en primer lugar, de las razones que contribuyen a explicar el renovado interés historiográfico por el estudio de las estructuras de poder local, y, en segundo lugar, y sobre todo, de los aspectos metodológicos que, en mi opinión, deberían tenerse en cuenta en todo análisis de dichas estructuras en el siglo XIX ${ }^{1}$. Por razones de tiempo, excluyo

1 Este texto debe bastante a las discusiones que he mantenido al respecto durante años con Jaume Suau, profesor del Departamento de Historia Contemporánea de la Universidad de Barcelona, aunque sólo yo soy responsable de sus errores y deficiencias.

Hiippania, LIX/1, núm. 201 (1999) 37-50 
de mi exposición el tema de las fuentes, aún a sabiendas de que los planteamientos que se sostienen condicionan el tipo de fuentes que se utilizan. En cualquier caso, dado el carácter de mi intervención, trataré de ejemplificar los aspectos metodológicos en la medida de lo posible, así como proporcionar la bibliografia pertinente, siempre tomando en consideración que este Encuentro se ocupa de cuestiones relacionadas con el poder político a diversos niveles territoriales. Por lo demás, debo aclarar que lo que voy a exponer es fruto de una serie de reflexiones elaboradas a lo largo de una investigación de historia comparada que ha durado hasta el presente dieciséis años, centrada en diversas localidades catalanas en el arco cronológico comprendido entre el último cuarto del siglo XVIII y el inicio de la Restauración ${ }^{2}$. Es mi deseo que pueda serles de alguna utilidad.

\section{RAZONES DE UN VIRAJE}

¿Por qué se ha pasado, historiogtáficamente hablando, de prestar poca atención a las estructuras de poder local a considerarlas relevantes?

2 Vid. E. Toscas, Aproximació a lestudi del poder local de Sarrià en 1840-1856, memoria de licenciatura, Premio Extraordinario, Universidad de Barcelona, 1986; E. TOSCAS y F. AYALA, «Entorn dels poders i les hisendes locals de dos municipis de Catalunya a mitjan segle XIX: Sarrià i Masquefa (1847-1856). Una anàlisi comparativan, en la obra colectiva, Fiscalitat estatal $i$ hisenda local (ss. XVT-XIX). Funcionament i repercussions socials, Palma de Mallorca, 1988, pp. 481-527; E. TOSCAS, «Sobre la qüestió política local a mitjan segle XIX. Aproximació a l'estudi de les relacions entre els poders locals i l'ajuntament al municipi de Sarrià en 18401856", Estudis d'Historia Agrària, n. 9, 1992, pp. 73-126; E.ToscAs, «Los estudios sobre el poder local en la Francia rural (ss. XVIII-XIX). Un comentario bibliográficon, Noticiario de Història Agrària, n ${ }^{\circ}$ 2, 1991, pp. 113-122; E. TOSCAS y F. AYALA, «Estat i vida política local: Sarrià i Masquefa a mitjan segle XIX", L'Aveng, n. 160,1992, pp. 38-40; E. TosCAS, "Elements de continuitat política local a la Barcelona del primer terç del segle XIX), Afers, n². 15, 1993, pp. 163-174; E. ToscAs, «Poder local y Revolución: balance crítico de un Coloquio Internacional», Noticiario de Historia Agraria, n. 6, 1993, pp. 143-149; E. Toscas, «Sentimiento de pertenencia local y territorio en una colectividad del Llano de Barcelona entre el Antiguo Régimen y el Estado liberal: Sarrià 1780-1860", Estudios Geográficos, tomo LV, n ${ }^{\circ}$ 216, 1994, pp. 503-529; E. TosCAs, «Poderes locales y Estado en la Cataluña del siglo XIX. Una investigación en curson, Bollettino del diciannovesimo secolo, $\pi^{\circ} .3,1994, \mathrm{pp} .60-62$; E. TosCAS, «Les rapports entre l'Etat et les pouvoirs locaux en Catalogne (1780-1850): bilan des recherches», en Roger DupUY (sous la direction de), Pouvoir local et Révolution 1780-1850. La frontiere intérieure, Rennes, 1995 , pp. 509-518; E. TosCAs, Estat i poders locals a la Catalunya del segle XIX a través d'un estudi de cas: Sarriá 1780-1860, tesis de doctorado, 2 vols., Universidad de Barcelona, 1995, «Premio Ciudad de Barcelona» de Historia 1995; E. TosCAs, «Els lligams polítics entre Barcelona i Sarriá en el segle XIX: la connexió Vives», Estudis Historics i Documents dels Arxius de Protocols, XIII, 1995, pp. 253-278; E. TosCAs y F. AYA.A,

Hicpunia, LIX/1, núm. 201 (1999) 37-50 
Creo que el renovado interés por su análisis se inscribe en el marco de una revisión bistoriográfica operada principalmente entre modernistas, sobre todo, y contemporaneístas en las dos últimas décadas con modalidades, ritmos, énfasis y tonos diversos según los países. Este revisionismo procede de la interacción entre, por un lado, una serie de mutaciones sociales y políticas acontecidas en este lapso de tiempo (proliferación de movimientos «regionalistas» o «étnicos» en estados industrializados, crisis del Estado-nación por presiones internas y externas, descrédito sin precedentes de la "gran política", a menudo alejada de la vida cotidiana, etc.), y, por otro lado, cambios en la temática y la orientación historiográficas (destacando al respecto la renovación epistemológica operada en historia política); en definitiva, la mutua influencia existente entre fenómenos sociales y pautas historiográficas en la Europa de los últimos veinte años.

Forma parte de dicho revisionismo una cada vez mayor atención hacia la dimensión territorial de los procesos históricos en un contexto de crisis de los modelos interpretativos dualistas (atraso/progreso; feudalismo/capitalismo; absolutismo/liberalismo; sociedad rural/mundo urbano; burguesía/proletariado, etc.). Por un lado, se percibe cada vez con mayor claridad que determinadas áreas geográficas, aún cuando sean contiguas, por una serie de factores naturales e históricos, reaccionan con ritmos y de modos muy diversos a las solicitaciones "externas». Por otro lado, los modelos dualistas (a menudo maniqueos) olvidan la interdependencia y las mediaciones existentes entre los «polos» opuestos. Todo esto ha puesto en tela de juicio lo que Pasquale Villani llama la "concepción unilineal y absolutamente progresista» del desarrollo histórico modelada de acuerdo con el «caso» inglés (que hacía que países como España o Italia, o sus áteas "attasadas», apareciesen como una suerte de (dnglaterras poco evolucionadas»), contraponiéndose a esta visión, dominante hasta los años 1960 (y tal vez más allá), «ña concepción pluralista, multilineal, una multiplicidad de modelos» ${ }^{3}$.

"Aspectes del poder politic local a la Barcelona del Trienni 1820-1823», Gausac, n. 7, 1995, pp. 39-43; E. TOSCAS, «a oposición campo-ciudad en Cataluña durante el Trienio liberal. Un estudio de cason, Trienio, $\mathrm{n}^{\circ} .28,1996$, pp. 15-50; E. TosCAS, «La visión del Estado en la historiografia española del siglo XIX», Bollettino del diciannovesimo secolo, $\mathrm{n}^{\circ}$. 6, 1997 (en prensa); $\mathrm{E}$. TOSCAS, "Conflitti e discorsi di legittimazione in una comunità locale catalana dell'Ottocenton, Quaderni Storici, 1997 (en prensa); E. TOSCAS, L'Estat i els poders locals a la Catalunya del segle XIX. Una visió des de Sarrià (1780-1860), Barcelona, 1997; E. TosCAs, "Centralización y "autonomías locales" bajo el Estado liberal en España. Una confrontación de normas con ptácticas», Hispania, 1998, núm. 198, pp. 213-232. E. TOSCAS y F. AYALA, «Secretarios municipales y construcción del Estado liberal en España», 1999 (en prensa); E. ToscAs, «Le poids du monde politique local dans la construction de l'Etat liberals, 1999 (en prensa).

3. Tomo la mayor parte de estas ideas de, A. MASSAFrA, «Le ragioni di una proposta», en A. Massafra (a cura di), I/ Mezzogiorno preunitario. Economia, società e istiturioni, Bari, 1988, pp. 5-20. Las citas de Villani en, P. VILLANI, «Un ventennio di ricerche: dai rapporti di proprietà all'analisi delle aziende e dei cicli produttivis, en A. Massafta (a cura di), Problemi di storia delle campagne meridionali nell'età moderna e contemporanea, Bari, 1981, p. 10. 
De acuerdo con esto, se ha fomentado la reducción de la escala de observación, en particular desde el marco nacional-estatal a los ámbitos regionales y locales. Eso ha ocurrido en buena parte de Europa y también, de una manera particular, en España 4.

Peto junto a la reducción de la escala de observación, que justifica que se tomen localidades (y regiones) como laboratorios de análisis, se ha producido una importante novedad en el marco de la historia política, al transmutarse ésta en ehistoria social del poder y de los grupos dirigentes» consagrada a reanudar en una unidad dialéctica economía, sociedad y política, y eso justo en el lugar que antes ocupaban la institución estatal y las cuestiones político-ideológicas ${ }^{5}$. Se le pide a la historia política, para llegar a ser «historia del poder», que confronte concepciones, normas y prácticas y que se comunique efectivamente con otras disciplinas (sociología, antropología etc.) $y$, antes que nada, con las otras «tamas» o «especialidades» académicas de la propia historia, es decir, que cruce sus datos con la historia social, económica, cultural (y no meramente los yuxtaponga, que es lo que más a menudo se práctica). Y ello, repito, con mucha conciencia del territorio (dimensión local, regional, estatal, supra-estatal etc.). Hay, pues, una preocupación dominante por dotar de contenido social el poder político a cualquier nivel territorial y por efectuar una historia de las instituciones que no sea, con unos u ottos retoques, fundamentalmente upolíticas. Pero lo que importa estudiar es ante todo el poder en todas sus manifestaciones (políica, social, económica, ideológica) y a todos los niveles territoriales. Lo que, obviamente, implica un cambio en la visión del Estado, y en particular del poder central.

Como señalaba Angelo Torre en 1983, «la formazione dello stato si presenta come un processo nel quale sono coinvolti i rapptesentanti del potere centrale, i gruppi dirigenti locali e le popolazioni sogette. A ben vedere si trata di

4 Sobre este último punto, vid. E. Toscas, «La visión del Estado en la historiografia espanola del siglo $\mathrm{XIX}$, op. cit.

5 Esta formulación procede de A. Musi, Stato e Pubblica amministratione nell'ancien régime, Nápoles, 1979, p. 7; tomo la teferencia de, A. MAssafra, Il Mexzogiorno preunitario, op. cit., p. 14. Vale la pena recordar, de acuerdo con Massafra, que historiadores italianos como $R$. Ajello, $G$. Galasso, G. Giarrizzo, P. Villani y R. Villari, todos ellos hoy ya de avanzada edad, alimentaron constantemente en los historiadores más jóvenes el cultivo de un enfoque de este tipo en historia política. Mientras tanto, en nuestras latitudes -más influidas por ciertas tradiciones francesas- se estimulaba precisamente el rechazo por la historia política de un modo bastante acrítico, y se propiciaban mucho más, entre otros, los estudios de historia económica y social. Por lo dernás, de la historiografía italiana nos llegó casi exclusivamente entonces la tradición de los Sereni, Zanghieri etc., tradición que -a pesar de su apariencia más (onarxista»- parece que no ha demostrado ni la solidez ni la continuidad ni la vitalidad de la primera, de la que le separaban relevartes objetos de controversia. Según esto, y vistas las cosas con perspectiva, todo indica que el «filtro» operado en los años 1970 y 1980 en España en relación con la historiografía italiana (donde tal vez los prejuicios ideológicos prevalecieron sobre los imperativos científicos) no nos benefició demasiado.

Hippania, LIX/1, núm. 201 (1999) 37-50 
un processo nel quale il termine mediano, le élites locali, costituiscono il piano di analisi più interessante e dinamico» ${ }^{6}$. Según el mismo autor, la propia autoridad estatal, en tanto que aparato de dominio, necesita de la mediatización constante en el plano local de grupos sociales específicos, los cuales se hacen representantes y depositarios de aquélla a cambio de recibir prestigio, elementos de dominio sobre las poblaciones etc. ${ }^{7}$. De modo que si se privilegian, como hasta ahora entre nosotros, los niveles político-institucionales centrales, se pierde de vista la complejidad de las articulaciones del poder político y las maneras como éste se relaciona con la sociedad civil.

Pero se puede decir más. Así, ya en una problemática más claramente ochocentista, me parece útil tener en cuenta, con Raffaele Romanelli, que hay «diferentes vías por las cuales los estados modernos extienden a la periferia su poder, vías que podrían clasificarse empíricamente en la medida en que utilizan los instrumentos de la integración forzosa, de la integración simbólica o de la mediación. Por eso no siempre nos encontramos en presencia de un corte totalitario en las articulaciones de la sociedad local, de tipo cruento o pedagógico (según el abstracto modelo jacobino); en muchos casos son respetadas en cierta medida las articulaciones preexistentes de los modelos autónomos y se puede hacer converger a las diferentes fi. delidades "tradicionales» hacia un centro simbólico o bien coordinarlas con complejos sistemas de transacción con poderes intermedios». En realidad, como subraya Romanelli, hay «diferentes vías de agregación [...] sin que sea posible establecer una "vía normal" ni una jerarquía entre los diferentes casos» ${ }^{8}$.

Plenamente justificado, pues, el hecho de que las estructuras de poder local juegan un papel social y político relevante, tanto bajo el Antiguo Régimen como durante los subsiguientes procesos de «modernización», paso a desarrollar los aspectos metodológicos que, a mi juicio, debería cubrir, o se podrian exigir, a todo estudio sobre las estructuras de poder local en el siglo XIX.

\section{ASPECTOS METODOLÓGICOS}

Sin ánimo de exhaustividad, y con la vista puesta en los procesos de construcción del Estado libetal (que, como ha señalado Romanelli, son procesos de

6 Vid. A.Toure, Stato e società nell'ancien régime,Turín, 1983, p. 13.

7 Vid A.Tolue, op. cit p. 13.

8 Vid. R. ROMANElu, cLa formación de los Estados nacionales en la Europa del siglo XIX. Notas sobre un proceso sociabr, en P. Ruiz Torres (ed.), Europa en su bistoria, Valencia, 1993, p. 57.

Hihpania, LIX/1, núm. 201 (1999) 37-50 
«nacionalización de la periferia»" "), me parece que pueden servir como marco de referencia los siguientes.

En primer lugar, parecen exigibles aspectos teóricos tales como la clarificación de la corriente o tendencia teórica sobre el poder a que se pertenece, autores de referencia etc., y también la definición de los conceptos sobre grupos y poderes locales que se utilizan. Eso ocurre a menudo en sociologia o antropología, y, en cambio, es menos frecuente entre historiadores ${ }^{10}$. Por tanto, hay que precisar en qué corriente se está y definir conceptos ("poden), "notables", «élites», "estado», "patronage» etc.)

En segundo lugar, cuestiones referentes a la unidad de análisis en relación con el objeto de estudio. Así, creo que habría que precisar cuál es la unidad, o cuáles son las unidades, de análisis cuando hablamos de la historia de los poderes locales; si, en vez de centrarse el estudio en una sola localidad, se utiliza una muestra de localidades, por ejemplo, hay que saber cuáles han sido los criterios de selección y si «todas» las generalizaciones son válidas para «todas» las unidades o sólo para algunas. En este sentido, por poner un ejemplo notable, hay que llamar la atención sobre los problemas que presenta la muestra de localidades que utilizó Jessenne para estudiar el «pouvoir au village» en Artois, región del norte de Francia, entre 1760 y $1848^{11}$. Por lo demás, hay que señalar los limites que siempre conlleva un estudio (cregionab) del poder local ${ }^{12}$.

En tercer lugar, todo un amplio espectro de otras cuestiones metodológicas, teferidas concretamente a las estructuras y relaciones de poder local. Voy a enumerar catorce, pero las voy a desarrollat desigualmente, de acuerdo con el carácter de este Encuentro. Son las siguientes:

1.a) ${ }_{2}$ De qué tipo de poder se está bablando? Se trata de poder ¿`económico? ¿político? ¿social? ¿ideológico? Como es sabido, entre historiadores, y en particular entre los del Ochocientos, está muy arraigada la tendencia a confundir "poder» con "poder político», cosa que en antropologia, por ejemplo, hace decenios que se ha superado, y no sólo nominalmente. Me parece pertinente recordar que

2 Vid. R. ROMANELlL, «La nazionalizzazione della periferia. Casi e prospettive di studio», Meridiana, $\mathrm{n}^{\circ} .4,1988$, pp. $13-24$, que constituye una magnífica introducción al número monográfico de dicha revista dedicado al tema «Poteri localis.

10 Como ya señaló oportunamente Jaume SuAU, «Metodología y fuentes para el estudio de las élites en España (1834-1936)", Noticiario de Historia Agraria, nº. 2, 1991, pp. 211-216.

11 Vid. J.P. Jessenne, Pouwoir au village et Révolution. Artois, 1760-1848, Lille, 1987.

12 He tratado esta cuestión en otros lugares: vid. E. ToscAS, «Los estudios sobre el poder local en la Francia rutal...», op. cit. y uLes rapports entre l'Etat et les pouvoirs locaux...» op. cit. Por lo que a mi respecta, he optado siempre por estudios «locales", en profundidad, de los poderes «locales" (lo que implica una reconstrucción contextualizada de los perfiles sociales de las comunidades o colectividades concernidas). $Y$ en esto, como en otros aspectos, estoy más cerca de los planteamientos italianos (muy influidos por la tradición anglosajona de los «estudios de comunidads) que de los franceses. En cuanto a los posibles límites epistemológicos de este enfoque, en particular la improcedencia de extrapolar un caso local a otros casos, de generalizar a toda una región o todo un estado lo que sólo ocurre en una localidad, o aún de perder de vista

Hijpania, LIX/1, núm. 201 (1999) 37-50 
"poderes locales» lo son tanto el terrateniente del lugar (poder económico) como el cura (poder ideológico) o el alcalde (poder político). La relación existente entre estos poderes y entre los mismos y el «exterion) ya es otro cantar.

2. ¿) ¿Cuál es el grado de autonomía de los poderes locales? Es una cuestión sumamente importante en el siglo XIX y en un Estado como el español, pero no sólo para este periodo y para este ámbito territorial. Pondré dos tipos de ejemplos.

a) La localidad catalana que yo más he estudiado, Sarrià, se hallaba a mediados del siglo XIX a unos cinco kilómetros de Barcelona, más de la mitad de sus tierras y casas estaban en manos de butgueses de dicha ciudad y, entre otras cosas, era también el predilecto lugar de veraneo y segunda residencia de la burguesía barcelonesa. De ello se siguía una fuerte dependencia de esta localidad tespecto a Barcelona (que es donde tenían su sede las autoridades más importantes de Cataluña, como es bien sabido). Sin embargo, no era infrecuente que a mediados del Ochocientos, incluso en una localidad así, las facciones en lucha por el poder político local (que eran coaliciones verticales rivales encabezadas por dos gtandes y antiguas familias) manipulatan al Gobernador civil, aunque éste fuera militar, no sin que ello tuvieta cierta base en la propia legislación municipal, concretamente la liberal-moderada, a menudo considerada particularmente centralista ${ }^{13}$. Pero un fenómeno parecido, es decir, la manipulación por las facciones locales de las autoridades superiotes, se ha detectado también en Sicilia en el siglo XIX, de acuerdo con E. Iachello ${ }^{14}$. Por lo demás, G. Gribaudi ha podido escribir al respecto sobre la Italia libetal lo siguiente: «Lo stato liberale, che pure aveva una rigida struttura di controllo dei comuni attraverso i prefetti e isottoprefetti, non aveva mai seriamente preso in considerazione l'opera di pacificazione locale: le fazioni venivano regolarmente denunciate, stigmatizate, ma mai seriamente combattute [...]. La risoluzione dei conflitti fu sempre lasciata alle comunita, al livello locales ${ }^{15}$. Ello enlaza con el segundo ejemplo, que no tiene que ver tanto con el

el marco global de referencia, creo que, si se admite que hay una crisis de la "síntesis tradicionals (criticable por centralista, elitista etc.) a causa de la multiplicidad de modelos que los estudios sobre el terreno están descubriendo, habrá que construir, bajo el estímulo de una fuerte preocupación teórica y sin dejar de dialogar con la historia general, una cnueva sintesis", socialmente y territorialmente mejor fundada, pero no por vía de yuxtaposición sino de comparación (eligiendo, por ejemplo, localidades con perfiles o comportamientos bien diferenciados). Lo que, dicho sea de paso, tampoco está exento de problemas que ahora, por razones obvias, no puedo abordar: remito al lector a P. MACRY, «Le élites urbane: stratificazione e mobilità sociale, le forme del potere locale e la cultura dei ceti emergentis, en A. MASSAFRA, I/ Mezzogiorno pretmitario, op. cit. pp. 799-820 y E. TOSCAS y F. AYALA, «Entorn dels poders i les hisendes locals de dos municipis de Catalunya a mitjan segle XIX...», op. cit. (Diré entre paréntesis que estos dos trabajos fueron publicados simultáneamente, en $1988, y$, sin conocerse sus autores, presentan notables paralelismos en sus planteamientos).

13. Vid E. Toscas, "Conflitti e discorsi di legittimazione..," op. cit.

$14 V$ id. E. InCHELLO, "Centralisation étatique et pouvoir local en Sicile au XIXe siècle», Annales E.S.C., enero-febrero de 1994, pp. 241-266.

$15 \mathrm{G}$. GRIBAudi, $A$ Eboli. Il mondo meridionale in cent'anni di trafformazioni, Venecia, 1990, pp. 162-163. Además, en el caso del Estado liberal español, parece inexistente no sólo la figura del 
funcionamiento real de las instituciones como con el de los partidos o las opciones políticoideológicas de ámbito estatal.

b) Como en tantos otros lugares de Italia, en la ciudad de Eboli en los años 1920 el partido fascista toma el poder local oficial. El «personal político» tradicional, generalmente dividido en dos facciones, es en parte barrido de la escena, pero el propio partido fascista, aunque es partido único, se impregna de la dinámica política imperante en el tejido social de la ciudad hasta el punto de que, sorprendentemente, se escinde también en dos bandos enfrentados, presentando uno de ellos no pocas analogías con una facción local tradicional ${ }^{16}$. Y si esto ocurria con el partido fascista en la Eboli del Mezogiorno de los años 1920 , algo parecido detectó Karnoouh en los años 1960 y 1970 con el partido comunista en el pueblo francés de Grand Fraud, en la Lorena: en las elecciones municipales, al contrario de lo que sucedía en las generales, miembros del PC francés, conocido por el rigor de su disciplina interna, se presentaban en listas alternativas y competían por el poder político local ${ }^{17}$.

Son ejemplos que invitan a hacerse preguntas relativas a la autonomía de los poderes locales y de la propia vida política local en relación con las instancias situadas fuera de la colectividad.

Conviene interrogarse: ¿cuál es la naturaleza y el alcance de las redes que aseguran la reproducción de los poderes locales «desde fuera» de la colectividad estudiada? ¿de qué modo se vertebran los poderes locales con otras instancias de poder que se sitúan fuera de la colectividad pero inciden sobre ella? (o, si se prefiere, ¿cuál es la trama social que une instancias locales y supra-locales de poder?); ¿qué relación, qué lazos existen entre las «élites» locales y la estructura nacional?

Quiero citar a este respecto una observación de R. Romanelli efectuada en 1988 y referida al poder político:

«non abbiamo una sola storia d'una prefettura, o del tessuto di rapporti che cotrono tra una prefettura e un comune non quindi la biografia d'un prefetto [...] che pure sarebbe assai utile, ma, su un piano ancora più «basso», la storia d'una politica prefettizian ${ }^{18}$.

Desde 1988 se han efectuado ya estudios en este sentido en Italia pero no así en España. Entiéndase bien: quiero decir que, por lo general, el estudio de la trama social existente entre instancias políticas regionales y locales se ha rehuido. Ello tiene que ver con una mentalidad historiográfica que parece renuente

subprefecto sino también la de los «comisarios gubernativos» a que hace referencia la autora (op. cit. p. 163). De modo que aún le era más dificil al Estado español intervenir institucionalmente en los conflictos locales.

16. Vid. G.Gribaudi, $A$ Eboli..., op. cit. cap. 9.

17 Vid. C. Kaknoouj, «La démoctatie impossible. Parenté et politique dans un village lorrainy, Etudes Rurales, n. 52, 1973, pp. 24-56. 188.

18 Vid. R. Romaneu., I/ comando impassibile. Stato e societa nellitalia liberale, Bolonia, 1988, p.

Hitpania, LIX/1, núm. 201 (1999) 37-50 
a cruzar los datos de la historia política con los de la historia social, en definitiva, a construir una historia social de las instituciones, lo que implica utilizar no sólo fuentes de historia política (las tradicionales y otras) sino también fuentes de la historia económica y social y aún conceptos, métodos y técnicas de la sociología y de la antropología. Por otra parte, parece claro que la relación entre instancias políticas locales y provinciales es más fácil de captar en las ciudades (especialmente en aquellas que albergan diputaciones, gobiernos civiles, consejos provinciales, juzgados, gobiernos militares etc.) que en los pueblos. A diferencia de lo que sucede en los pueblos pequeños, en las grandes ciudades los grupos dirigentes suelen tener al mismo tiempo una dimensión local y otra tegional y aún nacional: no son infrecuentes los casos de concejales que han sido o serán diputados provinciales, miembros del consejo provincial, gobernadores civiles, jueces, diputados a Cortes, senadores y/o ministros. Esta mezcla de niveles territoriales puede tener un correlato en el patrimonio material pero también puede no tenerlo: es algo que hay que estudiar en concreto. Pero, sea lo que fuere, si olvidamos el tejido de relaciones existente entre las ciudades y los pueblos, la construcción del Estado liberal -que implica, como ya se ha dicho, la «nacionalización de la periferia»- se hallará falta de datos básicos.

3.) La incidencia del Estado sobre la vida politica local. Creo que en este sentido hay que tener en cuenta una serie de aspectos que, en parte, he ejemplificado en otros ensayos ${ }^{19}$. Esos aspectos son, como mínimo, los siguientes:

- la "gestión" política local y el Estado

- la manera formal de acceder al poder (elección, disposición gubernativa)

- la concordancia o discordancia política entre las autoridades locales y las instancias gubernativas superiores

- la visión que tiene el Estado de los poderes locales

- las intervenciones del Estado en la vida política local

- las competencias que el Estado transfiere a los poderes locales

- el mantenimiento del orden social interno de la comunidad, que implica examinar la relación entre el orden (o el desorden) interno y externo

- las relaciones «intercomunales" y el Estado.

Pero no hay que contemplar sólo la incidencia del Estado sobre los poderes locales sino también la relación inversa.

4..) La incidencia de los poderes locales sobre el Estado, o sea, cómo influyen los poderes locales en la conftguración del Estado. En este sentido, me remito a los numerosos (aunque desiguales) trabajos existentes sobre las redes caciquiles en la Restauración realizados por historiadores gallegos, andaluces, murcianos, valencianos, catalanes, castellanos etc. que seria ocioso especificar aquí. Quisiera sólo traer a colación una reflexión de G. Gribaudi sobre el Mezzogiono contemporáneo, que creo aplicable a España: el Estado, aún cuando tenga una pre-

19. Vid. E. Toscas y F. AYalA, «Entorn dels poders i les hisendes locals de dos municipis de Catalunya...», op. cit:; E. TOSCAS, "Le poids du monde politique local dans la construction de l'Etat libérals op. cit. y L'Estat i els poders locals a la Catalunya del segle XIX, op. cit.

Hípanüa, LIX/1, núm 201 (1999) $37-50$ 
sencia masiva, incluso (pervasivau, toma las formas que la "sociedad locals impone 20 . De hecho, ello contribuye a explicar fenómenos como, por ejemplo, que la Guardia civil tenga en la segunda mitad del siglo XIX una significación social bien distinta en formaciones sociales tan diferentes como Andalucia y Cataluña ${ }^{22}$.

5.3) La delimitación de los agentes y de los depasitarios del poder: ‘en qué medida se encuentra concentrado y de qué modo se ha distribuido el poder?; en las élites y grupos de presión chay homogeneidad o bien una pluralidad de los mismos?; ¿qué tipo de enfrentamientos existen entre fracciones del bloque de poder?; ¿cuál es la base sociológica de los unotables» y de las «élites»?; ¿cuál es la importancia de las relaciones de parentesco, patronage etc?

De todos estos temas, tal vez el más descuidado por nuestra historiografía del Ochocientos es el de los conflictos locales, faccionalistas: a pesar de que los archivos municipales y provinciales están llenos de documentación relativa a este asunto, los historiadores pasan de puntillas por encima del mismo. Habria que saber exactamente por qué. Tal vez no se quiere admitir que la relación entre política nacional y política local no es unívoca, es decir, que a nivel local no hay una mera proyección o reproducción de los debates y tensiones «nacionales»; al fin y al cabo, como señala R. Romanelli, la historiografía política genetal casi nunca o muy raramente se ha interrogado sobre lo que significó ser conservador o progresista en una situación dada ${ }^{22}$.

\footnotetext{
20 Vid. G. GRIBAUDI, op. cit. p. 284.

21 Sobre este asunto, vid. E. TosCAS, L'Estat i els poders locals..., op. cit. cap. 2.

22. Vid. R. ROMANELLI, «La nazionalizzazione della periferia...n op. cit. Sobre la relación en tre conflictos locales e idiomas politicos, vid Quaderni Storici, $\mathrm{n}^{\circ}$. 63, 1986 (a cura di S. LOMBARDINI, O. RAGGIO, A. TORRE) dedicado a «Conflitti locali e idiomi politici». Sobre el faccionalismo en una comunidad rural del Mezzogiorno en el siglo XIX, G. CrviLE, I/ comune rustica Storia sociale di un paese del Mezrogionno nell'800, Bolonia, 1990. Sobre el faccionalismo de las élites locales de la región del Lazio y sobre las características de l: lucha política municipal después de la Unidad, vid. R. AGO, «Le città di provincia tra unificazione e prima guerra mondiale», en A. CARACciolo (a cura di), I/ Laqio, Turín, 1991, pp. 285-294. Sobre el tema del asociacionismo de élite como fase preparatoria de la organización política propiamente dicha, vid. Quaderni Storici, $\mathrm{n}^{\circ}$. 77, 1991 (a cura di A.M. BANTI e M. MERIGGI) dedicado a «Elites e associazioni nell'ltalia dell'Ottocentom. En cuanto a estudios españoles, vid. M.T. PÉrez PiCazo y G. Lemeunier, «Forme di potere locali nella Spagna moderna e contemporanea: dalle fazione al cacichismo nel regno di Murcia (secoli XVI-XIX), Cheiron, monográfico sobre «Padrini e clienti nell'Europa moderna», $n^{\circ} .5,1986$, pp. 105-131; M.T. PÉREZ PICAZO, «De regidor a cacique: las oligarquias municipales mutcianas en el siglo XIX), en P. SAAVEDRA y R. VILLARIS, Señores y campesinos en la Peninsula Iberica, siglos XVIII-XIX, Barcelona, 1991, vol. 1, pp. 16-27; G. LEMEUNiER, «Centralisme et autonomie locale. La guerre privée dans l'Espagne moderne. Un exemple murcienn, en la obra colectiva, Les élites locales et l'Etat dans l'Espagne moderne XVI-XIXe siècles, Paris, 1993, pp. 313-326; E. Toscas, L'Estat $i$ els Poders Locals..., op. cit., cap. 5. Finalmente, obras clave de referencia en antropología política son las de F.G. BAILEY, Stratagems and Spoils: A Social Antbropology of Politics, Oxford, 1969; J. Bolssevain, Friends of Friends. Networks, Manipulators and Coalitions, Oxford, 1974; S.W. SCrimiDT y otros, Friends, Followers and Factions. A Reader of Political Clientelism, Berkeley, 1977, por no citar sino tres ejemplos, entre otros que se podrian mencionat.
}

Higpanit, LIX/1, núm. 201 (1999) 37-50 
6.a) Los procesos de adquisición del pader: ¿cómo se consigue el poder? En particular, habría que esclarecer los procesos de control de las corporaciones locales, y ello confrontando normas institucionales con comportamientos efectivos, pues, como es bien sabido, en el Estado liberal bajo una apariencia formal de elección tiene lugar muchas veces de facto una cooptación o prácticas claramente endogámicas de acceso al poder. Hay que prestar atención a todos los mecanismos en obra (formales e informales, públicos y privados etc.).

En este sentido, habria que preguntarse por la posible voluntariedad $u$ obligatoriedad de la adquisición del poder. Así, dado que entre nosottos parece existir el prejucio de que «todo el mundo desea el poder», parece conveniente recordar que la adquisición del poder no siempre es querida: por ejemplo, la inhibición respecto a la detención de cargos municipales se ha detectado en ciertos grupos sociales acomodados en momentos de fuerte intervención del Estado en la vida política local, como entre los grandes arrendatarios de Artois en 1793-95, los hacendados de Sarrià (en el Pla de Barcelona) en 1840-43 y las grandes familias de propietarios de tierras de Pignataro Maggiore (a $45 \mathrm{~km}$. de Nápoles) en 1860-64, o sea, durante la Unidad ${ }^{23}$. Tal vez el uso de hombres de paja por parte de grandes propietarios agratios puede ser para éstos una forma de evitar la erosión política (como ocurre a menudo en la Cataluña rural de mediados del siglo XIX). Pero en otros casos la negativa a ocupar cargos municipales puede ser también una maniobra para ampliar el propio poder contractual ante las autoridades superiores ${ }^{24}$. Sea lo que fuere, parece pertinente interrogarse: ¿en qué momentos o circunstancias se desea o, al contratio, se rehuye el poder? Y cuándo se desea ¿qué se quiere obtener con él? ¿se pretende prestigio, apropiación de riqueza social, autoafirmación frente a otros? ¿cuales son las ideas o imágenes que movilizan más energías de cara a obtener el poder?

En cualquier caso, una vez adquirido el poder hay que plantearse otras cuestiones.

7.a) Los dominios, las instancias, las modalidades y las prácticas del ejercicio del poder. La formulación es genérica y su contenido limita y se imbrica con ottos puntos; pero aún así me ha parecido adecuado que constituyera un punto específico.

8.a) El ejercicio del poder: ¿qué se hace con el poder? ¿cómo varían las políticas concretas a lo largo del tiempo? ¿por qué se eligen determinadas políticas y se efectúan unas u otras opciones o decisiones? ¿qué consecuencias tienen estas opciones o decisiones? ¿existen contradicciones entre los que adoptan las decisiones y la diversidad de intereses que representan?

Quiero recordar que la historiografía hasta ahora ha centrado más su atención en el reclutamiento del upersonal político» local que en la efectiva gestión

23 Vid. J-P. JESSENNE, op. cit.; E. TosCAs, «Sobre la qü̈estió política local...», op. cit.; G. CJv1LE, op. cit.

24 Vid. G.MoricoLA, «Elite economica ed élite amministrativa della città di Avellino dopo il decennio napoleonicon, en A. MASSAFR (a cura di), I/Mezzogionno preunitario, op. cit., p. 840 .

Higpania, LIX/1, núm. 201 (1999) 37-50 
de éste, a pesar de que se percibe más quién manda estudiando la política que se lleva a cabo que analizando el gobierno que la ejecuta ${ }^{25}$.

9.) La estructuración del poder: ¿cómo se mantiene? ¿mediante qué mecanismos? ¿cómo se lleva a cabo la legitimación del poder? Sobre este último asunto existen algunos trabajos recientes ${ }^{26}$.

10.) La relación poderes/poblacion: ‘hay comunicación, y, en caso afirmativo, de qué tipo, entre grupos de poder -internos y externos-y base social?; chay relaciones de dependencia o de autonomía? ¿verticales u hotizontales?; los conflictos entre grupos de poder ¿involuctan a la población? ¿de qué modo se construyen relaciones verticales? Son asuntos que, por lo menos en parte, han tratado con particular acierto G. Civile y G. Gribaudi ${ }^{27}$. Quiero precisar que G. Civile, en su estudio sobre una comunidad rural del Mezzogionno, Pignatato Maggiore, presta mucha atención a profesiones liberales de importancia creciente en el siglo XIX como las de médico, abogado, notario etc. que ponían en relación élite y clases populares, sociedad y Estado; es decir, se trataba de elementos «mediadores» fundamentales.

11.2) La visión que tiene la gente de las autoridades. Me parece que es algo sobre lo que se sabe poquísimo. Teniendo en cuenta que el sigo XIX es considerado el siglo por excelencia de la "politización", de lo que Agulhon llama sha descente de la politique vers les masses» ${ }^{28}$, bueno será preguntarse: ¿cómo se percibín «desde abajo» el lenguaje, los mensajes y los gestos políticos emitidos «desde arribas? ¿qué imágenes o representaciones se formaban las gentes de sus superiores sociales, políticos, ideológicos más inmediatos, y aún de sus autoridades supra-locales? ¿cuáles eran las escalas de valores de las clases populares en relación con sus autoridades y, en particular, qué es lo que más apreciaban y detestaban de aquéllas? Y puesto que el lugar de «lo público» en la vida social fue constantemente debatido a lo largo del Ochocientos, ¿cuáles eran los límites de y entre la «esfera pública» y la «esfera privadas para las clases populares de las localidades? ¿de qué modo se operó y se modificó la interacción entre la concepción oficial, burguesa, de «bien público» y las nociones populares del mismo? En cualquiera de los casos, parece bueno tener pre-

25 Sobre la política que llevan a cabo los gobiernos municipales en el mundo urbano europeo entre la segunda mitad del siglo XIX y el primer cuarto del XX, una importante revista francesa ha publicado artículos de gran interés: vid. L. SCARPA, "Politique et bureaucratie. L'administration des notables à Berlin au XIXe siècle», Genèses, nº 7, marzo de 1992, pp. 129-149; R. RODGER, «L'interventionnisme municipal en Ecosse 1860-1914: civisme local, préoccupations sociales et intérêts des possédants», Genèses, n. 10, enero de 1993, pp. 6-30; C. SorBA, «L'heritage des remparts. Un cas de municipalisme démocratique en Italie: Parme 1889-1914», op. cit., pp. 31-52; L. MURARD y P. ZYLBERMAN, «Experts et notables. Les bureaux municipaux d'hygiène en France (1879-1914)", op. cit. pp. 53-73; M. HIETA1.A, «La diffusion des innovations: Helsinki 1875-1917», op. cit. pp. 74-89.

26 Remito al númeto de Quaderni Siorici, 1997 (a cura di G. Gribaudi) dedicado a «Conflitti, linguaggi e legitimazione».

27 Vid. G. Crvile, II comune rustico..., op. cit.; G. GrIBaudi, $A$ Eboli..., op. cit.

28 Vid. M. Agut.HON, La Republique ax village, Paris, 1970, cap. Vl. No entro ahora a discutir la validez de esta definición.

Hi.puniu, LIX/1, núm. 201 (1999) 37-50 
sente que la familia era una forma local de conocimiento y de clasificación y que la lógica de grupo predominaba sobre la lógica del ciudadano individual, que parece básicamente doctrinatia ${ }^{29}$.

12. $\left.{ }^{2}\right)$ La movilidad de los detentores del poder: ¿cómo se producen los cambios de poder? ¿qué grado de continuidad y de cambio experimentan las hegemonías locales, los bloques de poder local? Partiendo de la premisa de que existe una conexión entre cambios socioeconómicos y cambios en las estructuras políticas, opino que habría que telacionar los procesos de diferenciación y de integración social que conllevan la industrialización o la urbanización del Ochocientos con los cambios en las esferas y las instancias de poder. Y habría que analizar los factores que coadyuvan a los cambios en este sentido. En cualquier caso, me parecen particulamente ejemplares los análisis de la dinámica política local en colectividades concretas del Mezzogiorno (un pueblo y una ciudad) a lo largo de un siglo efectuados por G. Civile (Pignataro Maggiore, 1815-1915) y G. Gribaudi (Eboli, 1880-1980), ya citados.

13.) El poder como elemento de reproducción y de cambio. Parece que, sometido a una suerte de movimiento pendular, el poder ha pasado de ser considerado ante todo como un factor de cambio a ser visto principalmente como un factor de reproducción social (eso último en la década de los ochenta). Tal vez habría que tener en cuenta ambas funciones, que no son excluyentes, en los análisis sobre el poder que se realizan ${ }^{30}$. Quisiera recordar, de todos modos, que para los coetáneos el poder político local ha sido visto como un elemento de transformación social en ciertas coyunturas: M. Agulhon afirma que la insurrección popular de la Provenza francesa de diciembre de 1851 contra el golpe de Estado de Luís Napoleón «s'est joué dans les mairies" y, asimismo, una de las dos grandes medidas de los insurrectos fue el cambio de autoridades municipales ${ }^{31}$. Fuera de ha sociedad rural, en la ciudad industrial de Limoges, en abril de 1848 ula dissolution du conseil municipal [...] était le premier objectif de la Société populaires s2. Más dificil es demostrar el modo cómo el poder político local transforma realmente las relaciones sociales (Jessenne, por ejemplo, lo postula pero no lo demuestra).

29 Vid. P. MACry, Ottocento. Famiglia, élites e patrimonio a Napoli, Tutin, 1988.

30 Vid. G. Civile, «Continuità e mutamento in una comunità rurale nel secondo periodo botbonicon, en A. MASSAFR (a cura di), I/Mexzogionno preunitario, op. at. pp. 867-881. Según este autor, «la distinzione fra mutamento e continuità [...] è ưn procedimento in parte artificiale, poiché nell'analisi concreta non tiscontriamo dei momenti contrapposti, ma piuttosto un proceso continuo in cui il nuovo e il vecchio costituiscono due facce degli stessi fenomeni. [...] Occorre forse una precisazione. L'assenza di fratture traumatiche nella vita locale non implica che i fenomeni indicati si svolgano senza conseguenze conflittuali, o siano subiti dai diversi gruppi sociali come il portato di una logica superiore dei fatti. Non posiamo neppure interpretatli come il risultato di scelte esclusive della élite locale imposte all'insieme della comunità con un tapporto a senso unicon (op. cit., p. 869).

31 Vid. M. AGullon, op. cit. p. 452 y pp. 437-438, respectivamente.

32 Vid J.Merruman, Limoges, la ville rouge, Paris, 1991, p. 130.

Hi.pantia, LIX/1, núm. 201 (1999) 37-50) 
14.3) Tipologia y estudio comparativo de los "poderes locales» (en el sentido más amplio posible): habría que situar, comparar el caso estudiado poniéndolo en relación con otros casos o tipos; realizar una historia comparada de los sistemas de poder locales y regionales predominantes en diferentes paises de Europa occidental. 